\title{
Twenty Years of Experience in Juvenile Nasopharyngeal Angiofibroma (JNA) Preoperative Endovascular Embolization: An Effective Procedure with a Low Complications Rate
}

Andrea Giorgianni ${ }^{1}$, Stefano Molinaro ${ }^{1, *}{ }^{\oplus}$, Edoardo Agosti ${ }^{2}$, Alberto Vito Terrana ${ }^{1}$, Francesco Alberto Vizzari ${ }^{1}$, Alberto Daniele Arosio ${ }^{3,4}$, Giacomo Pietrobon ${ }^{5}$, Luca Volpi ${ }^{6,7}$, Mario Turri-Zanoni ${ }^{3,8}$, Giuseppe Craparo ${ }^{9}$, Filippo Piacentino ${ }^{10}$, Paolo Castelnuovo ${ }^{3,4,8}$, Fabio Massimo Baruzzi ${ }^{1}$ and Maurizio Bignami ${ }^{6,7}$

check for updates

Citation: Giorgianni, A.; Molinaro, S.; Agosti, E.; Terrana, A.V.; Vizzari, F.A.; Arosio, A.D.; Pietrobon, G.; Volpi, L.; Turri-Zanoni, M.; Craparo, G.; et al. Twenty Years of Experience in Juvenile Nasopharyngeal Angiofibroma (JNA) Preoperative Endovascular Embolization: An Effective Procedure with a Low Complications Rate. J. Clin. Med. 2021, 10, 3926. https://doi.org/ $10.3390 /$ jcm10173926

Academic Editor: Alexandre Bozec

Received: 23 July 2021

Accepted: 23 August 2021

Published: 31 August 2021

Publisher's Note: MDPI stays neutral with regard to jurisdictional claims in published maps and institutional affiliations.

Copyright: (c) 2021 by the authors. Licensee MDPI, Basel, Switzerland. This article is an open access article distributed under the terms and conditions of the Creative Commons Attribution (CC BY) license (https:/ / creativecommons.org/licenses/by/ $4.0 /)$.
1 Neuroradiology Unit, ASST Sette Laghi-Circolo Hospital, 21100 Varese, Italy; andrea.giorgianni@asst-settelaghi.it (A.G.); albertovito.terrana@asst-settelaghi.it (A.V.T.); francescoalberto.vizzari@asst-settelaghi.it (F.A.V.); fabio.baruzzi@asst-settelaghi.it (F.M.B.)

2 Department of Biotechnology and Life Sciences, Division of Neurosurgery, University of Insubria, 21100 Varese, Italy; edoardo_agosti@libero.it

3 Department of Biotechnology and Life Sciences, Division of Otorhinolaryngology, University of Insubria, 21100 Varese, Italy; albertodaniele.arosio@gmail.com (A.D.A.); tzm@inwind.it (M.T.-Z.); paolo.castelnuovo@me.com (P.C.)

4 Department of Surgical Specialities, Division of Otorhinolaryngology, ASST Sette Laghi-Circolo Hospital, 21100 Varese, Italy

5 Department of Head and Neck Surgery and Otorhinolaryngology, European Institute of Oncology IRCCS, 20122 Milano, Italy; giacomo.pietrobon@gmail.com

6 Department of Otorhinolaryngology, ASST Lariana, University of Insubria, 22100 Como, Italy; luca.volpi81@gmail.com (L.V.); bignami67@me.com (M.B.)

7 Department of Surgery, ASST Lariana, University of Insubria, 22100 Como, Italy

8 Head and Neck Surgery \& Forensic Dissection Research Center (HNS\&FDRc), Department of Biotechnology and Life Sciences, University of Insubria, 21100 Varese, Italy

9 Diagnostic and Interventional Neuroradiology Unit, ARNAS Civic Hospital, 90127 Palermo, Italy; gcraparo@yahoo.it

10 Radiology Unit, ASST Sette Laghi-Circolo Hospital, 21100 Varese, Italy; filippo.piacentino@asst-settelaghi.it

* Correspondence: stefanomolinaro52@gmail.com

Abstract: Juvenile nasopharyngeal angiofibroma (JNA) is a benign tumor of the nasal cavity that predominantly affects young boys. Surgical removal remains the gold standard for the management of this disease. Preoperative intra-arterial embolization (PIAE) is useful for reductions in intraoperative blood loss and surgical complications. In our series of 79 patients who underwent preoperative embolization from 1999 to 2020, demographics, procedural aspects, surgical management and followup outcome were analyzed. Embolization was performed in a similar fashion for all patients, with a superselective microcatheterization of external carotid artery (ECA) feeders and an injection of polyvinyl alcohol (PVA) particles, followed, in some cases, by the deployment of coils . Procedural success was reached in $100 \%$ of cases, with no complications such as bleeding or thromboembolic occlusion, and surgical intraoperative blood loss was significantly decreased. In conclusion, PIAE is a safe and effective technique in JNA treatment, minimizing intraoperative bleeding.

Keywords: JNA; embolization; interventional neuroradiology; HNS

\section{Introduction}

Juvenile nasopharyngeal angiofibroma (JNA) is a highly vascularized and histologically benign tumor of the nasal cavity and paranasal sinuses, with aggressive behavior and locally invasive growth patterns [1]. It comprises $0.05 \%$ of head and neck tumors and predominantly occurs in young boys, with a mean age of presentation of 15 years [2,3]. The best treatment to date remains surgical removal of the tumor [3]. Preoperative embolization is used for virtually all cases of JNA, resulting in reduction in intraoperative bleeding, 
occlusion of surgically inaccessible arterial feeding vessels, decreased operative time and improved surgical visualization, identification and protection of adjacent structures [4-6]. This results in a significant reduction in overall surgical complications and, despite some reports of safe resection without embolization, it is considered to be the standard of care in most centers [7-9]. In this study, we describe our single-center experience in preoperative JNA devascularization with the injection of polyvinyl alcohol (PVA) into major lesion feeders, highlighting the safety and efficacy of this technique. Furthermore, we put emphasis on the detection of external carotid artery (ECA)-internal carotid artery (ICA) anastomoses, defining the main red flags to be considered during preoperative intra-arterial embolization to avoid intraprocedural iatrogenic embolic complications.

\section{Materials and Methods}

\subsection{Data Collection}

The study was performed in compliance with the Helsinki Declaration and with policies approved by the Insubria Board of Ethics. All patients involved in the study signed a consent form to publish their clinical photographs whenever useful.

We performed a retrospective analysis of 79 patients treated surgically at our Institution for JNA between 1999 and 2020 who underwent PIAE of ECA branches with the sole usage of PVA. Angiographic patterns, Radkowski stage [10], surgical approach, surgical time, blood loss, age and follow-up imaging were also listed in the database in Appendix A. CT and MRI scans were performed in all patients in order to assess Radkowski stage (Figure 1).

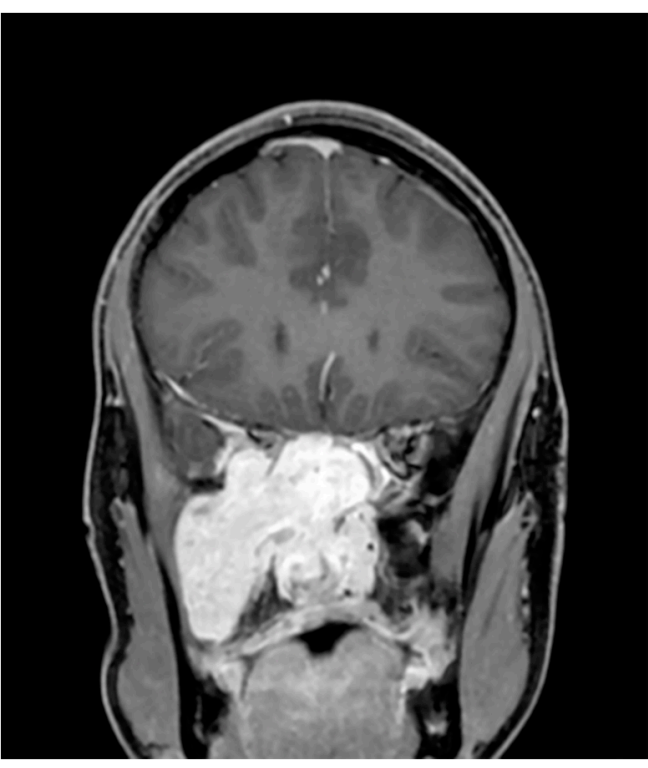

(a)

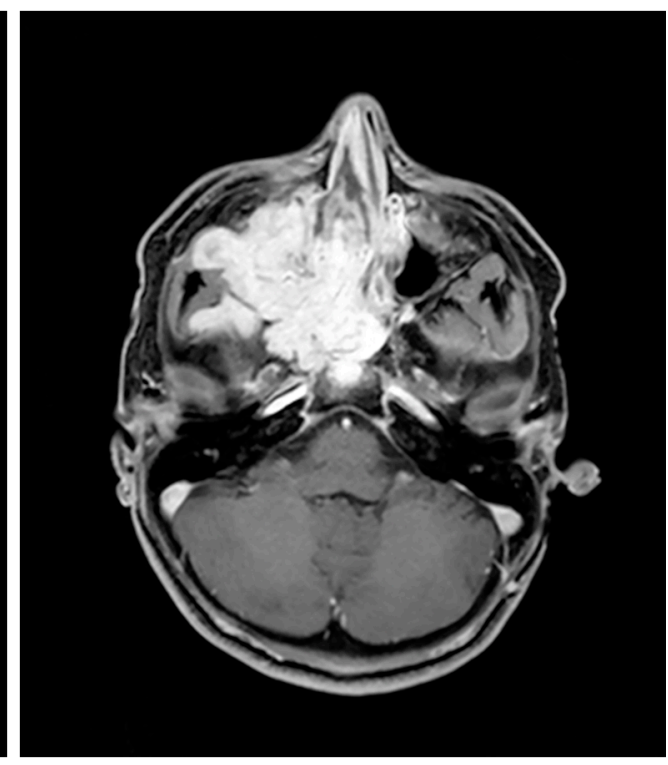

(b)

Figure 1. Preprocedural MRI scan (Gd-enhanced T1 Gradient-Echo 3D): coronal (a) and axial (b) views showing large JNA of right nasopharyngeal mass with expansion of the pterygopalatine fossa and extension into the infratemporal fossa.

The main outcomes considered were the incidence of complications related to embolization and/or surgery, residual disease rate and intraoperative blood loss.

\subsection{Endovascular Embolization}

The same approach was performed for every patient, with right groin puncture and placement of $6 \mathrm{~F}$ femoral sheath, catheterization of internal/external carotid artery (ICA/ECA) and vertebral artery (VA) with angiographic study of their vascular regions (Figure 2), followed by 6F guide catheter (Envoy MPC $90 \mathrm{~cm}$, Cordis) in proximal ECA and superselective catheterization of lesion feeders. Microcatheters used (Rebar 18, Medtronic; 
SL-10, Stryker) ranged from 0.0165 in to 0.021 in of internal diameters; guidewires used (Traxcess 14, Synchro 10, Synchro 14, Stryker) ranged from 0.010 in to 0.014 in. A control run was then performed from the microcatheter to look for dangerous collaterals and determine the precise position of the distal tip (Figure 3). Embolization was then performed using PVA particles (Contour, Boston Scientific, Marlborough, MA, USA) with different sizes—ranging from $250-355 \mu \mathrm{m}$ to $500-710 \mu \mathrm{m}$-in a slow infusion using blank roadmap visualization to achieve as proper distal penetration as anatomically possible until complete stasis of flow within each feeding vessel was achieved. Adjunctive coil embolization with GDC platinum coil was performed if particle embolization turned out to be incomplete, especially in the case of hypertrophied IMA. At the end of the procedure, control angiography was performed from both ICA and ECA to assess the percentage of tumor feeders embolized. Successful embolization was determined as a lack of contrast in the vascular territory of the embolized vessel (Figure 4).

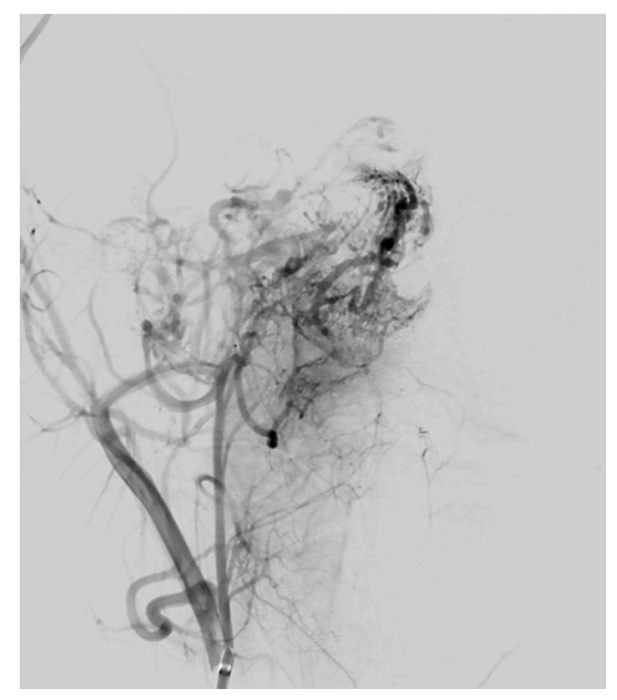

(a)

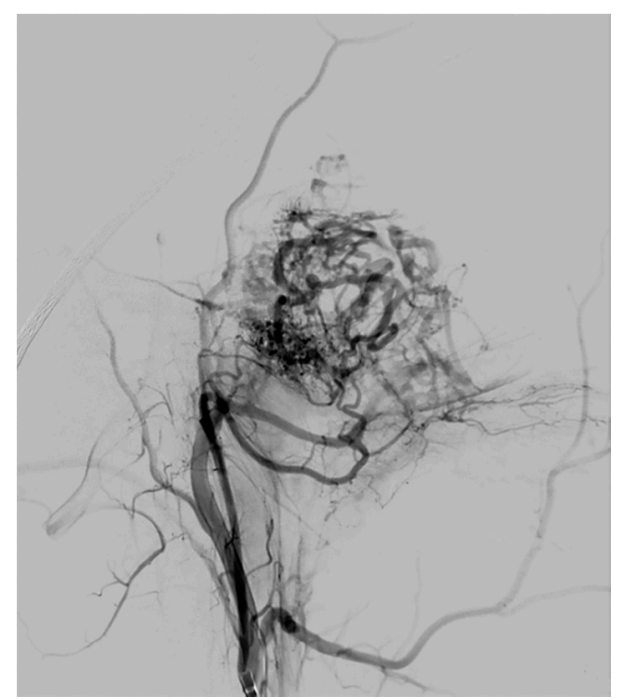

(b)

Figure 2. Preoperative DSA: selective catheterization of proximal ECA. Posteroanterior (PA) (a) and laterolateral (LL) (b) views of the JNA with major feeders from sphenopalatine branches of the distal internal maxillary artery (IMA) and from the ascending pharyngeal artery (APhA).

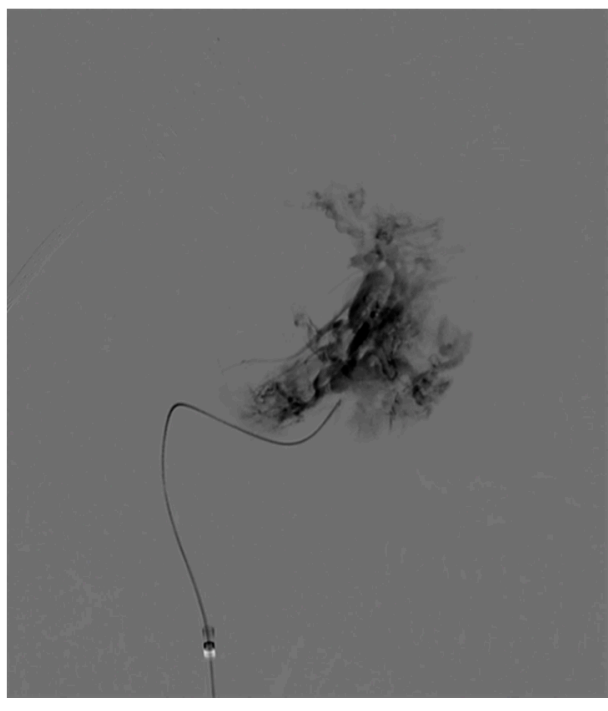

(a)

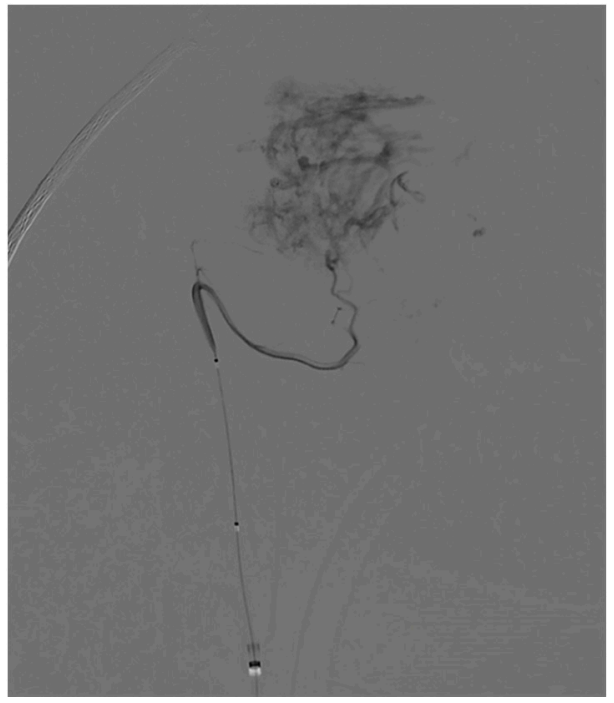

(b)

Figure 3. Intraprocedural DSA: PA view of superselective injection of distal IMA (a) and APhA (b) feeders. 


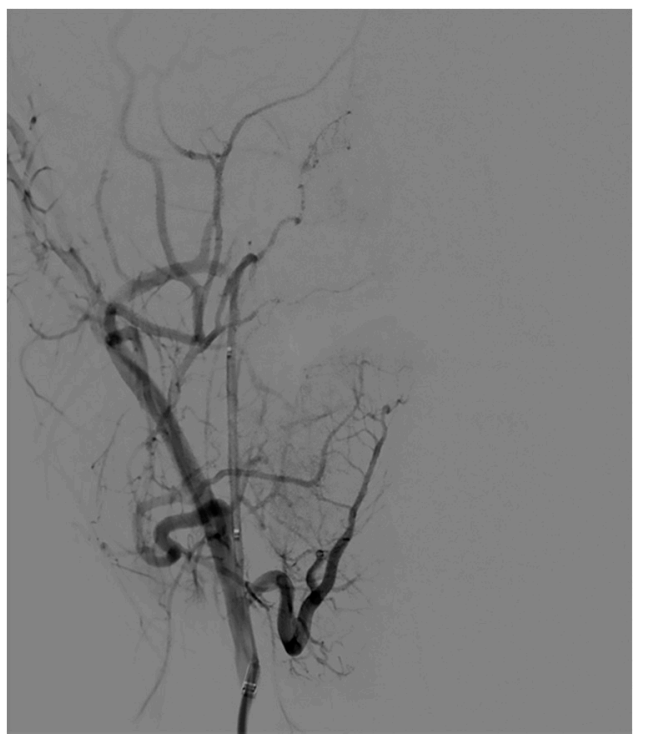

(a)

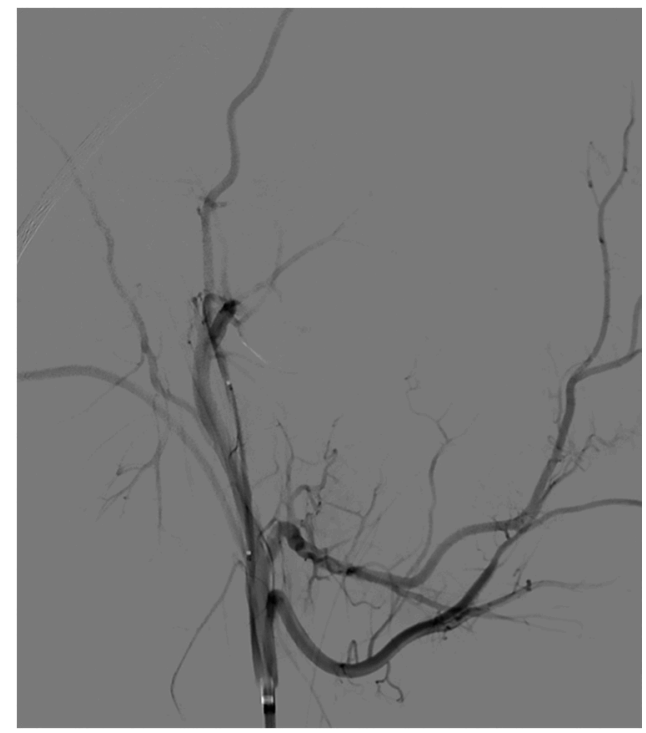

(b)

Figure 4. Postprocedural DSA: PA (a) and LL (b) views of the JNA showing successful embolization of the lesion.

\section{Results}

In total, 79 patients were included in this series. The mean age was 18 years (range $10-63$ years); all of them were male $(100 \%)$. The most common symptom was epistaxis (55\%), followed by nasal obstruction (50\%). According to the classification of Radkowski et al., $3 / 79(3.8 \%)$ type IA, $7 / 79(8.9 \%)$ type IB, $26 / 79(32.9 \%)$ type IIA, $7 / 79(8.9 \%)$ type IIB, $21 / 79(26.6 \%)$ type IIIA and $15 / 79(18.9 \%)$ type IIIB tumors were treated. PIAE with PVA intra-arterial injection was performed in all patients. All cases displayed tumor arterial supply from ECA and/or ICA circulations on 2D angiograms, with a total number of arterial tumor feeders embolized in a given session ranging between 1 and 5 .

The technical success of angiography and embolization of almost one big feeder was $100 \%$. Embolization of the JNAs was performed in all cases (79/79) (100\%); from distal sphenopalatine branches of the internal maxillary artery in $35 / 79$ cases $(44.3 \%)$; from ascending pharyngeal artery branches in $20 / 79$ cases (25.3\%); from an accessory branch of the middle meningeal artery (MMA) in $7 / 79$ cases $(8.9 \%)$; from the facial artery and a deep temporal branch of the MMA in $5 / 79$ cases $(0.6 \%)$; and, in $64 / 79$ cases $(81 \%)$, procedures were performed under general anesthesia, while the other $15(18.9 \%)$ were performed under conscious sedation.

There was no post-procedural bleeding and there were no thrombo-embolic cerebral ischemic complications in any patient. In no case were there any complications such as vascular dissections, groin hematomas or other complications related to vascular microcatheterization or embolization. Neck pain was experienced by a few patients, and was promptly resolved with analgesic medications. Tumors was removed in all cases within $24 \mathrm{~h}$ after embolization. All patients underwent surgery through an endoscopic endonasal approach. All patients were neurologically intact after surgery. Diagnosis of JNA was confirmed histopathologically after surgery.

Follow-up imaging was predominantly performed with MRI. Residual lesions were identified in $7 / 78$ patients $(8.9 \%)$. In post-surgical remnant JNA patients, the mean size of the preoperative lesion and the presence of vascular afferent from the ICA was greater than in JNAs, in which gross total resection occurred. Of all the post-surgical remnant JNAs, only $2 / 79(2.5 \%)$ underwent new surgical treatment. Demographic, clinical and surgical data of the 79 patients are summarized in Table 1. 
Table 1. Demographic, clinical and procedural characteristics of the 79 patients.

\begin{tabular}{ccc}
\hline Variables & & Data \\
\hline \multirow{2}{*}{ Age (years) } & Mean & 18 \\
& Median & 20 \\
& Range & $10-63$ \\
\hline \multirow{2}{*}{ Symptoms } & Epistaxis & $55 \%$ \\
& Nasal obstruction & $50 \%$ \\
& Rhinolalia & $14 \%$ \\
& Headache & $12 \%$ \\
& Proptosis & $10 \%$ \\
& Diplopia & $6 \%$ \\
Radkowski classification & Decreased visual acuity & $2 \%$ \\
\hline \multirow{2}{*}{ Intraoperative blood loss (mL) } & Type IA & $4 \%$ \\
& Type IB & $9 \%$ \\
& Type IIA & $33 \%$ \\
& Type IIB & $9 \%$ \\
& Type IIIA & $26 \%$ \\
& Type IIIB & $19 \%$ \\
\hline \multirow{2}{*}{ Surgical time (min) } & Mean & 784 \\
& Range & $40-5200$ \\
\hline
\end{tabular}

\section{Discussion}

In this study, we documented an excellent safety profile of PIAE with PVA, reporting no complications directly related to the embolization.

JNA is a rare, benign, vascular lesion of the skull base that affects young adolescent males most commonly between 9 and 19 years of age [3,10]. It is highly aggressive and associated with significant morbidity. Its tendency for skull base erosion, intracranial extension ( $20 \%$ of cases) and high vascularity (vascular component in a fibrous stroma with single endothelial lining) make surgical resection challenging, with a relevant risk for blood loss during resection, post-surgical remnants and lesion recurrence [9].

JNA commonly originates in the posterolateral wall of the nasal cavity, near the superior margin of the sphenopalatine foramen, with progressive diffusion to the anterior nasal cavity, maxillary sinus, pterygoid region, infratemporal fossa and middle cranial fossa [11-13]. Signs and symptoms are most often related to tumor extension into the nose, leading to nasal obstruction and epistaxis $[10,13,14]$. Feeding vessels usually arise from the external carotid system via the internal maxillary artery or ascending pharyngeal artery, but can be highly variable, often with heterogeneous vascularization patterns originating from contralateral ECA, petrous and cavernous branches of ICA, such as mandibulo-vidian artery, inferolateral trunk and ECA-ICA anastomosis, such as ethmoid branches of the ophthalmic artery, which are often related to bigger dimensions [15-17].

Traditionally, the open transfacial approach has been the gold standard for JNA excision [1]. In recent years, the advent of endonasal endoscopic approaches (EEAs) has revolutionized the surgical management of these lesions, reducing JNA post-surgical morbidity and recurrence rates [14]. The main advantages of the endoscopic endonasal route are better magnification of the lesion, the dissection of the surgical planes between the lesion and healthy tissue and better cosmetic outcomes. However, JNA resection can still be complicated by massive hemorrhaging because of a rich vascular supply [14,15].

In order to reduce intraoperative bleeding, facilitate surgical lesion removal and improve a patient's post-operative course, over time, preoperative embolization techniques 
have been established [18]. The main techniques used for preoperative JNA embolization are endovascular arterial catheterization and direct percutaneous puncture [16-19].

Pharmacological treatments also have been described to minimize the intraoperative bleeding. Thakar et al. described a significant difference between prepubertal and postpubertal patients in their response to flutamide. Indeed, in postpubertal patients, 6 weeks preoperative may lead to partial tumor regression, facilitating surgical excision and limit morbidity [20].

PIAE is the current most accepted treatment for JNA, minimizing intraoperative bleeding and reducing surgical morbidity $[15,17,21,22]$. This technique not only reduces the blood supply to the lesion, but the diagnostic preoperative digital subtraction angiography (DSA) highlights the JNA specific vascularization patterns, guiding the surgeon to plan the approach and to delineate lesion areas of increased bleeding risk $[15,23]$. However, the intra-arterial embolization has some technical limitations, mainly due to the presence of non-embolizable small feeders and to the vascular spasm caused by catheter endovascular manipulation [19]. Furthermore, the presence of ECA-ICA anastomosis directly involved in the vascular supply limits complete JNA devascularization for the risk of inadvertent injection of embolic material into ICA circulation by anterograde crossing from ECA branches through the tumor feeders $[16,23,24]$. These embolic complications can lead to retinal and cerebral strokes, with iatrogenic blindness and permanent brain damage [24-26].

The widely used standard approach for JNA is embolization with particles such as PVA, embospheres (Guerbet Biomedical, Louvres, France) and gelfoam (Upjohn Co., Kalamazoo, MI, USA), all of which have been used successfully for the PIAE of head/neck tumors, as well as in the central nervous system [15,22]. The use of liquid embolic agents (e.g., Onyx), also by percutaneous direct puncture, has been reported to allow for a deeper penetration to tumor capillaries with improved fluoroscopic visibility, as well as a lower risk of catheter adherence [17]. When using PVA, because of its irregular profile ("flakes"), a minimum particle size of more than $150 \mu \mathrm{m}$, with a range from 150 to $350 \mu \mathrm{m}$, is believed to provide the best compromise between safety (collaterals) and efficient devascularization. As only a temporary occlusion can be achieved, an interval no longer than 7 days between particle embolization and surgery is essential to ensure sufficient devascularization $[17,19,27]$.

\section{Conclusions}

In this retrospective analysis, PIAE has demonstrated itself to be a safe technique (absence of major intra- or periprocedural hemorrhagic or ischemic complications) and, above all, effective in reducing intraoperative bleeding. Additionally, offering improved intraoperative visibility also reduces postoperative JNA residual rates.

Author Contributions: Conceptualization, A.G., S.M., E.A. and M.B.; methodology, A.G., S.M. and E.A.; software, A.V.T., F.A.V. and A.D.A.; validation, G.P. and L.V.; formal analysis, S.M., E.A., A.D.A., M.T.-Z.; investigation, G.C.; resources, P.C., F.P. and F.M.B.; data curation, S.M.; writing-original draft preparation, S.M. and E.A.; writing-review and editing, A.G., S.M. and E.A.; visualization, A.G., F.M.B. and M.B.; supervision, A.G.; project administration, A.G. and P.C. All authors have read and agreed to the published version of the manuscript.

Funding: This research received no external funding.

Institutional Review Board Statement: The study was conducted according to the guidelines of the Declaration of Helsinki and approved by the Institutional Review Board (or Ethics Committee) of Insubria Board of Ethics.

Informed Consent Statement: Informed consent was obtained from all subjects involved in the study.

Data Availability Statement: Data are available on request due to restrictions, e.g., privacy or ethical reasons.

Conflicts of Interest: The authors declare no conflict of interest. 


\section{Appendix A}

Table A1. Demographic, procedural, surgical and follow-up data of patients treated in the cohort.

\begin{tabular}{|c|c|c|c|c|c|c|c|c|c|c|}
\hline Patient No. & Age & Date of Treatment & $\begin{array}{l}\text { Radkowski } \\
\text { Staging }\end{array}$ & Sedation & $\begin{array}{c}\text { Selective } \\
\text { Embolization }\end{array}$ & $\begin{array}{l}\text { Adjunctive } \\
\text { Coils }\end{array}$ & $\begin{array}{l}\text { Blood Loss } \\
\quad(\mathrm{mL})\end{array}$ & $\begin{array}{l}\text { Embo/Surgery } \\
\text { Complications }\end{array}$ & Persistence & $\begin{array}{l}\text { Surgery for } \\
\text { Recurrence }\end{array}$ \\
\hline 1 & 20 & 20 July 1999 & $\mathrm{IIb}$ & GA & IMA/APhA & No & 500 & No & No & No \\
\hline 2 & 10 & 18 November 1999 & Ia & CS & IMA & No & 400 & No & No & No \\
\hline 3 & 43 & 7 May2001 & IIIa & GA & IMA & No & 400 & No & No & No \\
\hline 4 & 18 & 15 May 2001 & IIa & CS & IMA & No & 400 & No & No & No \\
\hline 5 & 16 & 20 February 2002 & Ia & GA & IMA/APhA & No & 400 & No & No & No \\
\hline 6 & 13 & 28 February 2002 & IIIa & GA & IMA/APhA/FA & No & 650 & No & No & No \\
\hline 7 & 17 & 3 June 2002 & ІІа & CS & IMA & No & 200 & No & No & No \\
\hline 8 & 14 & 29 August 2002 & IIIb & GA & IMA/APhA & No & 2800 & No & Yes (CS) & No \\
\hline 9 & 31 & 12 November 2002 & IIIa & CS & IMA & No & 200 & No & No & No \\
\hline 10 & 19 & 28 January 2003 & ІІа & GA & IMA & No & 400 & No & No & No \\
\hline 11 & 16 & 12 March 2003 & IIIb & GA & IMA/APhA & No & 1500 & No & No & No \\
\hline 12 & 12 & 19 February 2004 & $\mathrm{IIIb}$ & GA & IMA/APhA/AM/DT & Yes & 800 & No & Yes (CS) & Yes $(6 / 12 / 2005)$ \\
\hline 13 & 12 & 2 February 2005 & IIa & GA & IMA & No & 450 & No & No & No \\
\hline 14 & 49 & 14 February 2005 & IIa & GA & IMA/APhA & No & 200 & No & No & No \\
\hline 15 & 16 & 21 February 2005 & Ia & CS & IMA & No & 300 & No & No & No \\
\hline 16 & 13 & 1 March 2005 & IIIa & GA & IMA & No & 700 & No & Yes (PPF) & No \\
\hline 17 & 10 & 14 March 2005 & IIIa & GA & IMA/APhA/AM & No & 1400 & No & No & No \\
\hline 18 & 29 & 13 June 2005 & IIIa & CS & IMA & No & 500 & No & No & No \\
\hline 19 & 36 & 5 September 2005 & IIIb & GA & IMA/APhA/FA & Yes & 2500 & No & Yes (CS) & No \\
\hline 20 & 15 & 29 November 2005 & IIIb & GA & IMA/APhA/AM & No & 1800 & No & Yes (CS) & No \\
\hline 22 & 19 & 9 March 2006 & IIa & CS & IMA & No & 200 & No & No & No \\
\hline 23 & 13 & 14 December 2006 & IIa & GA & IMA/APhA & No & 1500 & No & No & No \\
\hline 24 & 13 & 18 June 2007 & IIIa & GA & IMA & No & 350 & No & No & No \\
\hline 25 & 15 & 28 June 2007 & IIIa & GA & IMA/AM & No & 500 & No & No & No \\
\hline 26 & 17 & 12 July 2007 & IIa & GA & IMA & No & 200 & No & No & No \\
\hline 27 & 14 & 23 October 2007 & IIIb & GA & IMA/APhA/FA & Yes & 600 & No & No & No \\
\hline 28 & 15 & 11 June 2008 & IIIb & GA & IMA/APhA/AM & No & 700 & No & No & No \\
\hline 29 & 39 & 30 June 2008 & IIIb & CS & IMA & No & 200 & No & No & No \\
\hline 30 & 20 & 22 July 2008 & IIIb & GA & IMA/APhA/DT & No & 5200 & No & No & No \\
\hline 31 & 20 & 9 September 2008 & IIIb & GA & IMA/AM & No & 300 & No & No & No \\
\hline 32 & 14 & 30 September 2008 & IIIa & CS & IMA & No & 300 & No & No & No \\
\hline 33 & 14 & 11 November 2008 & IIa & GA & IMA/APhA/FA & No & 300 & No & No & No \\
\hline 34 & 21 & 2 December 2008 & $\mathrm{IIb}$ & GA & IMA/AM & No & 700 & No & No & No \\
\hline 35 & 18 & 17 February 2009 & $\mathrm{IIb}$ & CS & IMA & No & 1200 & No & No & No \\
\hline 36 & 26 & 16 June 2009 & IIIa & GA & IMA/APhA/DT & No & 600 & No & No & No \\
\hline 37 & 13 & 21 January 2010 & IIIa & GA & IMA/APhA/AM & No & 1000 & No & No & No \\
\hline 38 & 18 & 25 March 2010 & $\mathrm{IIb}$ & GA & IMA & No & 800 & No & No & No \\
\hline 39 & 13 & 11 May 2010 & IIa & GA & IMA & No & 300 & No & No & No \\
\hline 40 & 18 & 2 June 2010 & IIa & GA & IMA/APhA & No & 100 & No & No & No \\
\hline
\end{tabular}


Table A1. Cont.

\begin{tabular}{|c|c|c|c|c|c|c|c|c|c|c|}
\hline Patient No. & Age & Date of Treatment & $\begin{array}{l}\text { Radkowski } \\
\text { Staging }\end{array}$ & Sedation & $\begin{array}{c}\text { Selective } \\
\text { Embolization }\end{array}$ & $\begin{array}{l}\text { Adjunctive } \\
\text { Coils }\end{array}$ & $\begin{array}{l}\text { Blood Loss } \\
\quad(\mathrm{mL})\end{array}$ & $\begin{array}{l}\text { Embo/Surgery } \\
\text { Complications }\end{array}$ & Persistence & $\begin{array}{l}\text { Surgery for } \\
\text { Recurrence }\end{array}$ \\
\hline 41 & 20 & 9 November 2010 & II & GA & IMA & No & 1500 & No & No & No \\
\hline 42 & 16 & 29 November 2011 & $\mathrm{IIb}$ & GA & IMA/APhA & No & 550 & No & No & No \\
\hline 43 & 15 & 17 April 2012 & $\mathrm{Ib}$ & GA & IMA/AM & No & 250 & No & No & No \\
\hline 44 & 13 & 22 May 2012 & IIIa & GA & IMA/APhA & Yes & 600 & No & No & No \\
\hline 45 & 20 & 19 June 2012 & IIa & $\mathrm{CS}$ & IMA & No & 100 & No & No & No \\
\hline 46 & 14 & 26 July 2012 & IIIa & GA & IMA/APhA/AM & No & 800 & No & No & No \\
\hline 47 & 19 & 23 August 2012 & IIa & GA & IMA & No & 600 & No & No & No \\
\hline 48 & 17 & 4 September 2012 & IIa & GA & IMA & No & 400 & No & No & No \\
\hline 49 & 19 & 16 October 2012 & IIIa & GA & IMA/AM & Yes & 400 & No & No & No \\
\hline 50 & 19 & 8 January 2013 & IIa & GA & IMA & No & 300 & No & No & No \\
\hline 51 & 13 & 14 May 2013 & IIIa & GA & IMA/APhA/AM & No & 200 & No & No & No \\
\hline 52 & 13 & 19 June 2013 & $\mathrm{Ib}$ & GA & IMA & No & 500 & No & No & No \\
\hline 53 & 13 & 20 June 2013 & IIIa & GA & IMA & No & 2000 & No & No & No \\
\hline 54 & 63 & 24 June 2013 & IIa & GA & IMA & No & 500 & $\begin{array}{l}\text { Post-surgical } \\
\text { bleeding }\end{array}$ & No & No \\
\hline 55 & 11 & 25 June 2013 & IIIlb & GA & IMA/APhA & No & 1200 & No & Yes (CS) & No \\
\hline 56 & 13 & 27 August 2013 & IIa & GA & IMA & No & 800 & No & No & No \\
\hline 57 & 20 & 16 January 2014 & IIa & GA & IMA/AM & No & 250 & No & No & No \\
\hline 58 & 16 & 2 April 2014 & IIa & GA & IMA & No & 40 & No & No & No \\
\hline 59 & 16 & 29 September 2014 & IIIa & GA & IMA & No & 450 & No & No & No \\
\hline 61 & 12 & 25 February 2015 & $\mathrm{IIIb}$ & GA & IMA & No & 2000 & No & No & No \\
\hline 62 & 15 & 11 March 2015 & $\mathrm{IIIb}$ & GA & IMA/APhA/AM & No & 2100 & No & No & No \\
\hline 63 & 18 & 15 July 2015 & IIIa & GA & IMA/APhA/AM/DT/FA & A No & 1500 & No & No & No \\
\hline 64 & 35 & 20 January 2016 & IIIa & GA & IMA/APhA/DT/FA & No & 1000 & No & No & No \\
\hline 65 & 13 & 31 August 2016 & $\mathrm{IIlb}$ & GA & IMA/APhA/AM & No & 500 & No & No & No \\
\hline 66 & 12 & 22 September 2016 & $\mathrm{Ib}$ & GA & IMA/APhA/AM & No & 150 & No & No & No \\
\hline 67 & 16 & 7 June 2017 & IIa & CS & IMA & No & 200 & No & No & No \\
\hline 68 & 16 & 19 July 2017 & IIIa & GA & IMA/APhA/AM & Yes & 2500 & No & No & No \\
\hline 69 & 13 & 19 October 2017 & ІІа & GA & IMA/APhA & No & 150 & No & No & No \\
\hline 70 & 14 & 23 January 2018 & $\mathrm{Ib}$ & GA & IMA/APhA/AM & Yes & 200 & No & No & No \\
\hline 71 & 19 & 10 July 2018 & $\mathrm{Ib}$ & CS & IMA & No & 100 & No & No & No \\
\hline 72 & 16 & 16 August 2018 & $\mathrm{Ib}$ & CS & IMA & No & 50 & No & No & No \\
\hline 73 & 12 & 18 February 2019 & $\mathrm{IIb}$ & GA & IMA & No & 150 & No & No & No \\
\hline 74 & 15 & 26 June 2019 & IIa & GA & IMA/APhA & No & 500 & No & No & No \\
\hline 75 & 14 & 26 September 2019 & $\mathrm{IIb}$ & CS & IMA & No & 300 & No & No & No \\
\hline 76 & 18 & 28 November 2019 & $\mathrm{IIb}$ & GA & IMA & No & 100 & No & No & No \\
\hline 77 & 20 & 19 December 2019 & IIa & GA & IMA & No & 400 & No & No & No \\
\hline 78 & 15 & 4 May 2020 & IIa & GA & IMA/APhA/FA & No & 2000 & No & No & No \\
\hline 79 & 13 & 30 November 2020 & IIIb & GA & IMA/APhA & No & 2500 & No & No & No \\
\hline
\end{tabular}

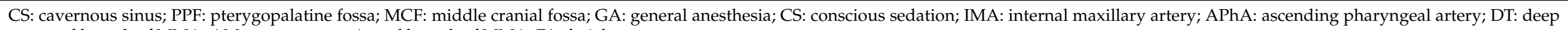
temporal branch of MMA; AM: accessory meningeal branch of MMA; FA: facial artery. 


\section{References}

1. Adil Shroff Makhasana, J.; Kulkarni, M.A.; Vaze, S.; Sarosh Shroff, A. Juvenile nasopharyngeal angiofibroma. J. Oral Maxillofac. Pathol. 2016, 20, 330. [CrossRef]

2. Overdevest, J.B.; Amans, M.R.; Zaki, P.; Pletcher, S.D.; El-Sayed, I.H. Patterns of vascularization and surgical morbidity in juvenile nasopharyngeal angiofibroma: A case series, systematic review, and meta-analysis. Head Neck 2018, 40, 428-443. [CrossRef]

3. Alshaikh, N.A.; Eleftheriadou, A. Juvenile nasopharyngeal angiofibroma staging: An overview. Ear. Nose Throat J. 2015, 94, E12-E22. [CrossRef]

4. Ballah, D.; Rabinowitz, D.; Vossough, A.; Rickert, S.; Dunham, B.; Kazahaya, K.; Cahill, A.M. Preoperative angiography and external carotid artery embolization of juvenile nasopharyngeal angiofibromas in a tertiary referral paediatric centre. Clin. Radiol. 2013, 68, 1097-1106. [CrossRef] [PubMed]

5. Maroda, A.J.; Beckmann, N.A.; Sheyn, A.M.; Elijovich, L.; Michael, L.M.; DiNitto, J.M.; Rangarajan, S.V. Trimodal embolization of juvenile nasopharyngeal angiofibroma with intracranial extension. Int. J. Pediatr. Otorhinolaryngol. 2020, 130, 109805. [CrossRef] [PubMed]

6. Lutz, J.; Holtmannspötter, M.; Flatz, W.; Meier-Bender, A.; Berghaus, A.; Brückmann, H.; Zengel, P. Preoperative embolization to improve the surgical management and outcome of juvenile nasopharyngeal angiofibroma (JNA) in a single center: 10-year experience. Clin. Neuroradiol. 2016, 26, 405-413. [CrossRef]

7. Rosenbaum-Halevi, D.; Lopez-Rivera, V.; Turkmani, A.; Sanzgiri, A.; Zeineddine, U.H.; Luong, A.; Roc, P. A safer endovascular technique for pre-operative embolization of juvenile nasopharyngeal angiofibroma: Avoiding the pitfalls of external carotid artery-Internal carotid artery anastomoses. J. Cerebrovasc. Endovasc. Neurosurg. 2020, 22, 97-105. [CrossRef] [PubMed]

8. Leong, S.C. A systematic review of surgical outcomes for advanced juvenile nasopharyngeal angiofibroma with intracranial involvement. Laryngoscope 2013, 123, 1125-1131. [CrossRef]

9. López, F.; Triantafyllou, A.; Snyderman, C.H.; Hunt, J.L.; Suárez, C.; Lund, V.J.; Strojan, P.; Saba, N.F.; Nixon, I.J.; Devaney, K.O.; et al. Nasal juvenile angiofibroma: Current perspectives with emphasis on management. Head Neck 2017, 39, 1033-1045. [CrossRef]

10. Radkowski, D.; McGill, T.; Healy, G.B.; Ohlms, L.; Jones, D.T. Angiofibroma. Changes in staging and treatment. Arch. Otolaryngol. Head Neck Surg. 1996, 122, 122-129. [CrossRef]

11. Nicolai, P.; Schreiber, A.; Bolzoni Villaret, A. Juvenile angiofibroma: Evolution of management. Int. J. Pediatr. 2012, $2012,412545$. [CrossRef]

12. Rowan, N.R.; Zwagerman, N.T.; Heft-Neal, M.E.; Gardner, P.A.; Snyderman, C.H. Juvenile nasal angiofibromas: A comparison of modern staging systems in an endoscopic era. J. Neurol. Surg. B Skull Base 2017, 78, 63-67. [CrossRef]

13. Carrillo, J.F.; Maldonado, F.; Albores, O.; Ramírez-Ortega, M.M.; Oñate-Ocaña, L.F. Juvenile nasopharyngeal angiofibroma: Clinical factors associated with recurrence, and proposal of a staging system. J. Surg. Oncol. 2008, 98, 75-80. [CrossRef]

14. Snyderman, C.H.; Pant, H.; Carrau, R.L.; Gardner, P. A new endoscopic staging system for angiofibromas. Arch. Otolaryngol. Head Neck Surg. 2010, 136, 588-594. [CrossRef]

15. Gargula, S.; Saint-Maurice, J.P.; Labeyrie, M.A.; Eliezer, M.; Jourdaine, C.; Kania, R.; Wassef, M.; Adle-Biassette, H.; Houdart, E.; Herman, P.; et al. Embolization of internal carotid artery branches in juvenile nasopharyngeal angiofibroma. Laryngoscope 2021, 131, E775-E780. [CrossRef]

16. Santos-Franco, J.A.; Lee, A.; Campos-Navarro, L.A.; Tenorio-Sánchez, J.; Zenteno, M.; Osorio-Alvarado, A.R. Bilateral nonsuperselective embolization with particles under transient occlusion of the internal carotid artery in the management of juvenile nasopharyngeal angiofibroma: Technical note. Vasc. Endovasc. Surg. 2012, 46, 559-564. [CrossRef] [PubMed]

17. Lv, M.M.; Fan, X.D.; Su, L.X.; Chen, D. Preoperative direct puncture embolization of advanced juvenile nasopharyngeal angiofibroma in combination with transarterial embolization: An analysis of 22 consecutive patients. Cardiovasc. Interv. Radiol. 2013, 36, 111-117. [CrossRef] [PubMed]

18. Hackman, T.; Snyderman, C.H.; Carrau, R.; Vescan, A.; Kassam, A. Juvenile nasopharyngeal angiofibroma: The expanded endonasal approach. Am. J. Rhinol. Allergy 2009, 23, 95-99. [CrossRef] [PubMed]

19. Petruson, K.; Rodriguez-Catarino, M.; Petruson, B.; Finizia, C. Juvenile nasopharyngeal angiofibroma: Long-term results in preoperative embolized and non-embolized patients. Acta Otolaryngol. 2002, 122, 96-100. [CrossRef] [PubMed]

20. Thakar, A.; Gupta, G.; Bhalla, A.S.; Jain, V.; Sharma, S.C.; Sharma, R.; Bahadur, S.; Deka, R.C. Adjuvant therapy with flutamide for presurgical volume reduction in juvenile nasopharyngeal angiofibroma. Head Neck 2011, 33, 1747-1753. [CrossRef] [PubMed]

21. Borota, L.; Mahmoud, E.; Nyberg, C.; Ekberg, T. Combined percutaneous and transarterial devascularization of juvenile nasopharyngeal angiofibroma with protection of internal carotid artery : A modification of the technique. Interv. Neuroradiol. 2015, 21, 390-396. [CrossRef]

22. Narayanan, T.; Shilpee, J.; Sharma, B. Imaging in Juvenile Nasopharyngeal Angiofibroma : Clinical Significance of Ramharan and Chopstick Sign. Indian J. Otolaryngol. Head Neck Surg. 2017, 69, 81-87. [CrossRef]

23. Gao, M.; Gemmete, J.J.; Chaudhary, N. A comparison of particulate and onyx embolization in preoperative devascularization of juvenile nasopharyngeal angiofibromas. Neuroradiology 2013, 55, 1089-1096. [CrossRef] [PubMed]

24. Trivedi, M.; Desai, R.J.; Potdar, N.A.; Shinde, C.A.; Ukirde, V.; Bhuta, M.; Gopinathan Nair, A. Vision loss due to central retinal artery occlusion following embolization in a case of a giant juvenile nasopharyngeal angiofibroma. J. Craniofac. Surg. 2015, 26, e451-e453. [CrossRef] [PubMed] 
25. Vazquez, A.; Shukla, P.A.; Choudhry, O.J.; Gandhi, C.D.; Liu, J.K.; Anderson Eloy, J. Geometric alopecia after preoperative angioembolization of juvenile nasopharyngeal angiofibroma. Allergy Rhinol. 2013, 4, e21-e24. [CrossRef] [PubMed]

26. Tawfik, K.O.; Harmon, J.J.; Walters, Z.; Samy, R.; de Alarcon, A.; Stevens, S.M.; Abruzzo, T. Facial palsy following embolization of a juvenile nasopharyngeal angiofibroma. Ann. Otol. Rhinol. Laryngol. 2018, 127, 344-348. [CrossRef]

27. Safadi, A.; Schreiber, A.; Fliss, D.M.; Nicolai, P. Juvenile angiofibroma: Current management strategies. J. Neurol. Surg. B Skull Base 2018, 79, 21-30. [CrossRef] 